\title{
Một vài nét đặc sắc trong "Đất còn phù sa và Gió trên đồi hoang" của nhà văn Huỳnh Thạch Thảo
}

\author{
Truoong Thi Thu Thanh ${ }^{a^{*}}$ \\ ${ }^{a}$ Trưòng Đại học Phú Yên \\ *Email: truongthuthanhdhpy@gmail.com
}

\section{Thông tin bài viết}

Ngày nhận bài:

27/02/2018

Ngày duyệt đăng:

$10 / 9 / 2018$

Tù khoá:

Huỳnh Thach Thảo, truyện ngắn Huỳnh

Thạch Thảo, Đất còn phù sa, Gió trên đồi hoang.

\section{Tóm tắt}

Đến với văn học nghệ thuật Phú Yên, bạn đọc không thể bỏ qua tác giả Huỳnh Thạch Thảo - một trong những cây bút viết truyện ngắn đặc sắc với nguồn cảm hứng ngay chính trên mảnh đất quê hương của anh. Các tác phẩm của Huỳnh Thạch Thảo mang nhiều chi tiết thiên nhiên và thế sự với giọng văn nhẹ nhàng trong phong cách riêng của tác giả.
1. Hành trình sáng tạo và phong cách nghệ thuật của nhà văn Huỳnh Thạch Thảo

\subsection{Hànhtrình sáng tạo}

Chữ duyên trong Phật giáo rất gắn bó gần gũi với người dân Việt Nam. Tất cả mọi việc trên đời này đều xuất phát từ chữ duyên. Cũng như cái duyên cái nghiệp đã đưa đẩy Huỳnh Thạch Thảo đến với con đường viết văn mà không phải chủ đích ngay từ đầu lựa chọn của anh. Đến với nghề văn như một sự duyên nghiệp, Huỳnh Thạch Thảo ngày càng vững bước trên con đường riêng văn chương của mình. Bằng chứng cho sự phát triển nghề viết văn của tác giả Huỳnh Thạch Thảo là các giải thưởng mà anh đã đạt được qua các kỳ thi viết truyện ngắn danh giá của nước nhà. Các giải thưởng văn học như: Giải thưởng văn học của tổ chức Raddo Bamen và Bộ Giáo dục - Đào tạo (1991), giải thưởng Tác phẩm Tuổi xanh của Báo Tiền phong (1997), giải Nhì (không có giải Nhất) cuộc thi sáng tác Văn học Tầm nhìn thế kỷ (1999 - 2001) của Báo Tiền phong, giải thưởng Văn học tỉnh Phú
Yên lần thứ nhất (1975 - 2000), lần thứ hai (20002005), lần thứ ba (2005-2010).Tác phẩm được đánh dấu sự nghiệp văn chương của anh là Mùa phrợng, xuất bản vào năm 1998. Sau đó, cứ đều đặn hàng năm, nhà văn đất Phú lại được ra mắt công chúng bạn đọc với những tập truyện ngắn hay như: Gió trên đồi hoang (1999), Đất còn phù sa (2001), Tiếng vọng đồng rùng (2003), Bên dòng sông Ba Hạ (2004), Nhũng mùa hoa cỏ (2004), Chuyện trăm năm (2005), Vục con gái (2006)... Mới đây nhất là tập truyện ngắn Nguời con bên một dòng sông(2014), Sông xuôi về biển (2014).

\subsection{Phong cách nghệ thuật}

Khảo sát qua các tác phẩm của Huỳnh Thạch Thảo cũng như những lời bình phẩm từ các nhà văn hay từ các bài viết, chúng tôi có thể khái quát một số nét tiêu biểu nhất về phong cách sáng tác nghệ thuật của ông.

Truyện ngắn của nhà văn đất Phú đa dạng về nội dung và cũng rất phong phú về hình thức nghệ thuật. Ông hướng đến nhiều đề tài xoay quanh trong cuộc 
sống thường nhật trên chính mảnh đất quê hương của mình. Những cảnh thiên nhiên tươi đẹp đầy lãng mạn nhưng cũng không kém phần hoang dã, đầy dữ dội. Những người dân quê ngày đêm lam lũ với nghề bắt cá, nghề trồng lúa, khốn khổ, cơ cực nhưng lại không nguôi hướng về tương lai tươi sáng. Trong quá trình sáng tác, Huỳnh Thạch Thảo chủ yếu chỉ dựng lên những nhân vật, những cảnh đời hết sức chân thật bằng tình cảm con người với con người. Sự chân thật đầy nghĩa tình ấy được kết tinh từ những mảnh ghép của quê hương. Không gian làng quê như in vết hằn trong tâm trí ông. Trong ký ức một thời, Huỳnh Thạch Thảo như đưa bạn đọc trở về quá khứ qua lối văn hối cố. Nỗi ám ảnh thời gian như khắc khoải trong lòng tác giả để tạo nên một Huỳnh Thạch Thảo đầy chuyên nghiệp với nhiều sự trải nghiệm, đầy nhạy bén về trực giác.

Với giọng văn đầy ấm áp, đầy chất thơ, truyện ngắn Huỳnh Thạch Thảo được kết cấu như một bài thơ nhẹ nhàng. Đặc biệt, trong hầu hết các tác phẩm của nhà văn Huỳnh Thạch Thảo, cái kết bao giờ ông cũng để trống, buông lửng, gợi mở.

\section{Nhìn từ phương diện nội dung nghệ thuật}

2.1. Thiên nhiên hoang dã, dũ dội nhung cũng đầy lãng mạn nên tho

Về thăm Phú Yên, mọi người ít ấn tượng bởi cảnh đẹp hùng vĩ hay sự dữ dội của thác nước như cao nguyên. Đến với cao nguyên Vân Hòa hay leo lên ngọn Đá Bia hoặc Ngọn Hải đăng, mọi người đều có thể cảm nhận sự hoang sơ, đẹp mộc mạc về thiên nhiên nơi đây. Vì vậy, thiên nhiên Phú Yên được miêu tả trong truyện ngắn của Huỳnh Thạch Thảo phần lớn đều mang sự bình yên, đơn sơ. Chỉ những khi trời mưa bão thì sự dữ dội của con nước quanh con sông làm thiệt hại tài sản người dân nơi đầu nguồn.

Trong tập truyện ngắn Gió trên đồi hoang có lẽ ở trang 16 , hay trang 121, bạn đọc mới cảm thấy hết những sự khắc nghiệt của thiên nhiên. Nơi không gian biển cả, sóng vỗ rì rào bởi những hàng dương xao động vào những ngày giáp tết với khí trời se lạnh. Đưa bạn đọc lên không gian cao hơn của thượng nguồn. "Nước nguồn sau cơn mưa tuôn xuống cuồn cuộn trắng lấp loá rồi ầm ầm lao qua chiếc chòi rẫy chơ vơ không một điểm tựa, tôi nghe tiếng thét của H'Thu vang vọng rồi tất cả chao đảo, tất cả như muốn ngã nghiêng răng rắc sụp đổ rơi ra khoảng không rồi cuộn tròn trong xoáy lốc của nước, của đá, của những tán cây bị quăng quật tơi bời cùng cơn mưa rừng lại ập xuống quất mạnh vào mặt vào lưng bỏng rát trong đêm đen thẩm. Tôi quờ quạng nắm lấy những gì có thể bấu víu, lại tuột, lại rơi cuốn đến kiệt sức rồi lại bị tung lên nhào xuống để sặc nước, để thả trôi và tung lên lần nữa với cú va chạm khiến tôi bất tỉnh" H’Thu đã chết sau cơn giận dữ đất trời. Với giọng văn dồn dập mang lại cảm giác kinh hoàng từ mưa bão mà Huỳnh Thạch Thảo đã miêu tả rất cụ thể trong đoạn văn của mình. Cũng trong tập truyện ngắn Đất còn phù sa, độc giả cảm thấy nhẹ nhàng, vui tươi với sắc màu của mùa xuân với sự khoe sắc trong nắng của những cánh mai. Hình ảnh "từng chùm, từng chùm năm cánh toả màu huyết dụ đỏ rực cùng nắng hanh vàng mỗi độ xuân về, cành nhánh khẳng khiu bạc thếch nhưng có một sức sống tiềm tàng nhất ở những cánh rừng heo hút ít dấu chân người được dặt chân đến" [2, tr.39]. Cảnh đẹp nên thơ càng thêm lung linh, lấp lánh dưới sự hoà nguyện sơn nước hữu tình mà tác giả đã miêu tả trong đoạn văn ngắn. Tạo hóa đã ban tặng cho con người một bức tranh thiên nhiên tươi đẹp.

“Trong gió ngàn cuộn thổi, xào xạc tiếng lá khô lăn tròn nơi thung lũng ấy, có những nụ non và lộc biếc đâm chồi run rẩy, lung linh trong gió rồi bật lên trong nắng hanh, gió se lành lạnh một dải lụa vàng dài xa tít tắp, những cánh hoa dần rụng cho những nụ tơ khác bật lên sắc vàng năm cánh hoa mai. Dưới đất, dày kín hoa vàng. Nước suối trôi trôi màu vàng huyền ảo. Nắng vàng, hoa vàng cùng nền trời xanh lồng lộng tạo nét đẹp đến ngơ ngẩn" $[1$, tr.103].

Màu tím cũng được Huỳnh Thạch Thảo lựa chọn làm tông điểm khi ông dùng bút để chấm phá về vẻ đẹp lãng mạn của thiên nhiên Phú Yên. Xanh vàng, lộc biếc muôn phương trong sắc trời mùa xuân thì mùa hạ cũng bớt chói chang của đầm thấm, dịu nhẹ với màu tím hoa sim. "Cả tấm thảm tím hoa sim rung rung chuyển động trong gió, trong màu tím thẩm của đồi cô quạnh trong cả màu tím hoang sơ hoa cỏ chảy tràn xuống lòng suối nơi chân đồi hắt ngược và hòa nguyện màu tím trầm mặc đến rưng rưng buồn buồn của vùng đèo Mây đang trôi dần vào buổi hoàng hôn" [1, tr.108]. Lần giở từng trang truyện ngắn, chúng tôi lại bắt gặp đoạn văn miêu tả cảnh thiên nhiên nên thơ khác. Đó là hình ảnh dòng sông đang mênh mang trong gió thổi rập rờn lau lách. Phía ngoài xa những chiếc ghe câu cá cũng thả ánh sáng chập chờn trôi nổi trong ánh trăng mùng sáu tỏa mờ. Không gian im lắng, 
thỉnh thoảng tiếng quẩy của cá làm mặt sông gợn sóng" [2, tr.56]. Một không gian yên, nhẹ nhàng và đầy lãng mạn xóa tan những tháng ngày mưa bảo, nước thượng nguồn chảy về làm ngập, lụt, sói mòn, có khi những cơn động rừng làm đe dọa cả tính mạng con người.

Tóm lại, qua việc khảo sát hai truyện ngắn Gió trên đồi hoang và truyện ngắn Đất còn phù sa của nhà văn Huỳnh Thạch Thảo, chúng tôi tạm khái quát cảnh thiên nhiên thật tiêu biểu qua một số trang viết mang tính đặc trưng. Cảnh thiên nhiên hoang dã, dữ dội bên cạnh những cánh hoa rừng không kém phần tươi sắc. Thiên nhiên khắc nghiệt cũng là nguyên nhân dẫn đến nhiều cảnh đời lam lũ của những người lao động nghèo khổ, nhất là những người dân quanh con sông.

\subsection{Hình ảnh những ngưò̀ dân lao động nghèo khổ}

Hình ảnh những người dân lao động nghèo khổ cũng được nhà văn Huỳnh Thạch Thảo đặc biệt chú ý đến như một phần quan trọng không thể thiếu trong quá trình sáng tác của ông. Những mảnh đời với số phận khác nhau nhưng ở đây chúng tôi chỉ khảo sát trong hai tập truyện ngắn Đất không còn phù sa và truyện ngắn Gió trên đồi hoang.

Trong tập truyện ngắn Đất không còn phù sa, ở trang 56, Huỳnh Thạch Thảo đã phác họa lên bức tranh về cuộc sống của những dân cư quanh dòng sông. Chợ Xép là nơi trao đổi buôn bán và nơi ngự cư của những người nghèo khổ. "Sau những cảnh nhộn nhịp, khi chiều về, ghe thuyền rời bến, kẻ bán người mua không còn, hình ảnh những người dân nghèo khổ hiện lên ảm đạm”. Đó là hình ảnh về: gia đình gã Chuột có bốn người, mẹ con thằng Còm, thằng Còm bị liệt từ nhỏ, Nam gù độc thân làm khuân vác, Hoa lé làm nghề gánh nước thuê. Họ ở phía các sạp bán trái cây kề dãy mắm muối. Phía xa nơi sạp cá áp bến sát bãi cỏ lau là những gia đình đông người làm đủ nghề. Đó là những "mái lều lợp tranh ẩm mốc, lối đi bẹp nhẹp những mùi nước bốc mùi tanh tưởi" [2, tr.56]. Cuộc đời bị liệt, nhân vật Còm cả đời sống dưới chân của muôn hạng người. Cả ngày, nó vẫy vùng dưới "dòng nước chưa trôi hết các vỏ rau héo, giấy gói vương vãi, có chỗ còn nhờ nhờ đỏ do các mẹ bán thịt đem nhúng mủng xuống nước cọ rửa" $[2$, tr.58,]. Những người nghèo khổ ở nơi đây họ phải trải qua những ngày tháng vất vả, cơ hàn có khi đến oái oăm. Nhân vật Còm với thân hình tật nguyền ngoài việc phải cùng chung cảnh đời với làng xóm, người thân nơi góc chợ Xép, nó còn phải hứng chịu tất cả mọi sự nhơ nhuốc nhất lên người nó: đủ hạng bàn chân, dép guốc, nước bọt sình lầy. Mẹ con nó thì ngủ trên manh chiếu rách. Cuộc sống những người nơi gần sông luôn rình rập những nguy cơ khi nước nguồn lên. Mưa xối xả, tiếng nước réo rắt, cuộn xiết. Vì quá mong được đổi đời mà Nam đã bơi trong nước lũ để quay về lấy bằng được tấm vé số dù cho hành động đó có thể cướp đi tính mạng của anh. "Bóng Nam gù bơi phăng phăng, vượt lên những cơn nước phía xa rồi khuất dần, khuất dần dưới làn mưa rây rấy" $[2, \operatorname{tr}$. 68]. Những con người nghèo khổ quanh đây vẫn dắt díu nơi chợ Xép ngày này qua tháng khác, cực khổ, cơ bần. Nhưng cái nghèo vẫn đeo bám họ. "Phía sạp, Nam gù vương vãi những tấm vé số, có cái dính bết vào thành sạp gặp nắng khô cong rồi theo gió bay phấp phới, có cái không theo dòng nước mà đọng lại rải đều xuống dần vực sông" [2, tr.68]. Cái nghèo đói, lạnh lẽo bám lấy cuộc đời họ hằn lên nước da, khuôn mặt. "Những con người miền lũ nước da thâm tím, mặt bệch đi vì đói bên những đứa bé mắt tròn đen ngơ ngác nhìn ra từ các mái lều dựng tạm" [2, tr.123]. Họ quẩn quanh với cuộc đời đã an bài sẵn không lối thoát. "Cuộc sống miền lũ đến khắc nghiệt mỗi khi vào mùa, nghiệt hơn là bến đàn bà vẫn âm thầm tồn tại thời gian, trai gái lớn lên thành vợ thành chồng trong vòng trôn ốc đảo "Con kiến mà leo cành đa".

Mỗi cuộc đời mỗi số phận khác nhau nhưng người dân quê lao động bằng nghề làm nông hay đánh bắt cá ven sông thật khó thay đổi hoàn cảnh sống. Cái nghèo khổ vẫn đu bám dai dẳng số phận của họ. Một vòng tròn khép kín như trôn ốc đảo. Tất cả hình ảnh về những con người có cuộc sống khó khăn ấy luôn là niềm khắc khoải trong lòng nhà văn Huỳnh Thạch Thảo. Và cũng từ ấy, từ niềm thương cảm Huỳnh Thạch Thảo đã khơi nguồn cảm hứng viết văn của mình.

\subsection{Phú Yên một thời lịch sủ̉}

Trong truyện ngắn Huỳnh Thạch Thảo, Phú Yên về một thời lịch sử cũng hiện diện không kém phần ác liệt. Cùng với đó, những cảnh đau thương, tàn khốc của chiến tranh cũng được tái hiện qua nhiều trang viết một cách cụ thể.

Nhắc đến chiến tranh đồng nghĩa với việc nhớ về những cảm xúc buồn bã, những cơn ác mộng của bom đạn, của giặc thù. Bọn giặc đã gây ra bao nhiêu cảnh chết chóc, gây ra bao nhiêu nước mắt, sự hoang mang đến người dân Việt nói chung và dân Phú Yên nói 
riêng. Có nhiều nơi, "tiếng khóc tiếng réo như át hẳn tiếng gầm rít của từng loại máy bay tiêm kích, của bom toạ độ, của Cachiusa" [1, tr.38]. Hình ảnh những ngôi nhà tan nát, súng ống vất lăn lóc, bừa bãi cùng người chết. Một cảnh vô cùng tan thương trong dòng máu người vẫn đỏ sủi bọt trên đường nhựa. Chiến tranh thấm vào máu thịt vào cả thiên nhiên, đất trời nơi đây. "Phía xa, đợt gió của đại ngàn tiếp tục đỗ xuống ào ạt và gió từ thung lũng sông Ba thổi lên réo rắt, để hợp lại vun vút, cuồng nộ như thít chặt không trung, như tái hiện hàng loạt bước chân rầm rập, hỗn loạn, nức nở, ai oán và lại yên lặng” [1,tr.35]. Trong thời bom rơi lửa đạn, đâu đâu cũng nhuốm màu đỏ của máu, tiếng khóc, tiếng réo. "Phía ngã 6 đã dày đặc từng cụm khói lan toả trong tiếng đì đùng của súng, lựu đạn, kho tiếp liệu. [1, tr.38]. Còn lại đó, sau những cơn thịnh nộ dữ dội, những trận mưa bom là một "không gian im ắng chỉ tồn tại từng cụm khó, bãi lau cuồn cuộn, mùi khét lẹt của thay người chết cháy và nhũng đống thịt xương vung vãi, nhoè nhoẹt với đồ đạc. Rồi lại ồn ào, lại khóc, tiếng gào thét chửi bới gọi tìm nhau văng vẳng” [1,tr.42]. Nơi đâu cũng có xác người nằm xuống. Chiến tranh cũng là nguyên nhân của sự nghèo đói và bệnh tật cho con người. Hình ảnh Sông $\mathrm{Ba}$ đẹp lãng mạn giờ đây đã trở thành nghĩa trang khổng lồ vì đói, bệnh tật" [1,tr.44]. Chính chiến tranh đã gây ra bao đau thương đối với con người. Nhân vật Huyên trong truyện ngắn Đêm không tiếng bom rơi không đêm nào đối với chị là bình yên. Ban ngày chị là người vợ bình thường nhưng nữa đêm là thời gian chị đang sống giữa chiến tranh đầy tiếng bom. "Chị vùng dậy chạy ra vườn hét lên hoảng loạn, đêm không là giấc ngủ bình yên' $[1$, tr.86]. "Với chị đêm dầy rẫy những hình ảnh chết chóc, hồi tưởng về những biến động đau thương của một vùng quê hương khói lửa, đếm với chị đầy tiếng bom rơi”. Những ai đã trải qua chiến tranh đều có những ký ức đau thương. Họ một mình vật vã với chính những ký ức ây. Chiến tranh đã trở thành nỗi ám ảnh lớn cho tất cả những ai đối diện với chiến tranh.

Chiến tranh qua đi nhưng những hậu quả mà nó gây ra vô cùng lớn đến nỗi không thể xóa mờ. Chiến tranh đã trở thành vết hằn lên tất cả con người và kể cả thiên nhiên. Từ thế giới cho đến Việt Nam, chiến tranh là nỗi ám ảnh lớn kinh hoàng nhất và khủng khiếp nhất đối với những ai đã trải qua. Và, có lẽ đó, Huỳnh Thạch Thảo đã tốn rất nhiều bút lực để viết về đề tài này. Dù ông sinh năm 1963 đến khi giải phóng nước nhà năm 1975 nhưng trong 12 năm ấy cũng đủ để ông thấm thía cảnh tan thương và tàn khốc của chiến tranh. Có những truyện ngắn ông viết về chiến tranh từ lời kể, từ những chứng tích lịch sử nhưng bằng cảm xúc của mình, Huỳnh Thạch Thảo đã mang đến cho bạn đọc những trang văn đầy ác liệt về chiến tranh.

\section{Nhìn từ phương diện hình thức nghệ thuật}

\subsection{Không gian và thời gian hối cố}

Khảo sát hai tập truyện ngắn Đất còn phù sa và Gió trên đồi hoang, chúng tôi nhận thấy các tác phẩm củanhà văn Huỳnh Thạch Thảo sử dụng khá nhiều thời gian và không gian mang màu sắc hối cố. Những ký ức ngày xưa trở về trong tâm trí anh của một thời chiến tranh, một thời tuổi thơ vất vả với cuộc sống cơ hàn.

Cuộc đời nghèo khó của những con người lao động làm ăn lam lũ. Dòng sông $\mathrm{Ba}$ - nơi quen thuộc của người dân Phú Yên lãng mạn nên thơ với dòng nước phẳng lặng. Nhưng chính chiến tranh đã biến dòng sông trong mát nhuốm màu máu đỏ. Dòng sông Ba nơi những người bắt cá, nơi tụ họp buôn bán để sinh sống đã biến thành nghĩa trang khổng lồ trong phút chốc. Phú Yên cũng hứng chịu biết bao cơn giận dữ từ đất trời tạo ra sự đa dạng về thiên nhiên. Mở đầu đoạn văn "lâu rồi, lúc tôi còn nhỏ. Ông nội tôi từng kể huyền thoại về ma lai..." [1, tr.104], tác giả đưa người đọc dần về với những câu chuyện của quá khứ. Truyện ngắn $K y ́$ ức đồng rù̀ng ngay tên của tác phẩm cũng đã thể hiện không gian và thời gian hối cố. Câu chuyện được xây dựng dựa trên dòng hồi tưởng của tác giả. Một dòng ký ức trôi về, những chuyện ngày xưa hiện diện và được tác giả trần thuật lại với giọng văn nhẹ nhàng. "Đồng rừng nơi tôi ở trước kia còn gọi là xóm Hóc. Nơi ấy, ban đầu chỉ khoảng hai mươi nóc nhà trong một thung lũng được nối liền con đường mòn phía sau lưng núi Chóp" [1, tr.154]. Mạch văn cứ vậy mà trôi theo lời người kể chuyện của xóm Hóc. Trong không gian và thời gian quá khứ "tôi nhớ, từ chiếc cầu gỗ bắc qua con suối có một cây thị lớn, tán phủ rợp mấy ô ruộng với gốc sần sùi đầy hang bọng cho cả bầy tắc kè bông làm nơi trú ngụ" [1, tr.156]. Đầu đoạn văn với câu "tôi nhớ" như cánh cửa thời gian đang chuẩn bị mở ra những câu chuyện của ngày xưa và người kể chuyện ở đây chính là bà nội. Đồng rừng hay xóm Hóc cũng chứa đựng bao nhiêu nỗi niềm bởi nó gắn với nghĩa trang - nơi những người đã chết vì chiến tranh. "Nghĩa trang chang nắng và gió tứ bề thổi dội, từ triền đồi thoi thỏi có những đàn bò gặm cỏ bên 
những bụi dủ dẻ" [1, tr.166]. Thời gian ngưng đọng trong không gian quen thuộc ngày xưa. Trong tập truyện ngắn Gió trên đồi hoangngay đến với tựa đề Câu chuyện của quá khứ cũng làm cho bạn đọc mang sẵn tâm trạng hứng chờ một sự kiện, sự việc sẽ xảy ra ở một thời ngược với hiện tại. Một thời chiến tranh, xoay quanh nhân vật Jon HarKins và những năm tháng anh làm nhiệm vụ trên nước Việt Nam. Đó là “chuyện đã qua rồi để đất nước này có thêm một lịch sử và đang cố gắng là những gì đã mất bởi chiến tranh" [1, tr.32]. Thời gian luôn trôi theo quy luật tự nhiên của nó nhưng trong tâm lý mỗi chúng ta, thời gian có khi đứng lại, có khi trôi thật chậm nhưng cũng có lúc trôi thật nhanh. Quá khứ, hiện tại nhiều khi cùng tồn tại trong một thời điểm của cảm xúc. Thời gian như ngừng trôi, tình yêu càng thêm sâu. Con người càng chiêm nghiệm về những gì của cuộc sống, về cuộc đời, về tình cảm. Quá khứ dường như là sự ám ảnh thường xuyên trên mỗi trang viết của nhà văn. Nó vẫn hiện diện trong cuộc sống hiện tại, qua đồ vật, cảnh vật, để nhắc nhở người ta về những chuyện đã qua. Quá khứ không còn là điều gì vô hình nữa mà nó hiện ra cụ thể, có hình có khối để khẳng định sự tồn tại của mình trong hiện tại. Có lúc, quá khứ nhập thẳng vào cảm giác của con người, tạo ra hiện tượng ảo giác.

Xã hội ngày càng phát triển, con người luôn đổi thay để hoà nhập cùng cuộc sống hiện tại. Sự hối hả của cuộc sống mưu sinh khiến con người lao mình vào phía trước để làm việc mong có tương lai tươi sáng. Ngày tháng lặng lẽ trôi, họ vô tình lãng quên những điều đã qua. Và chỉ khi nào, trong không gian chứa nhiều kỷ niệm khó phai, bao ký ức nối đuôi nhau lần lượt trở về thì họ mới xao xuyến, tạm quên đi hiện tại để sống lại một thời quá khứ. Thời gian quá khứ quay về nơi không gian xưa cũ, con người đang hiện diện.

Một sự đồng hiện về không gian, thời gian diễn ra trong một con người.

\subsection{Ngôn ngũ dân dã, mộc mạc mang đậm chất phương nẫu}

Ngôn ngữ đánh dấu sự phát triển của loài người. Cũng như vậy, trong văn chương nghệ thuật, ngôn ngữ là thước đo tài năng của một nhà văn. Bởi lẽ, ngôn ngữ chính là chất liệu tạo nên tác phẩm văn học. Vốn ngôn ngữ giàu có sẽ là cơ sở cho sự linh hoạt trong việc lựa chọn từ góp phần tạo nên sự hoàn mỹ của tác phẩm và danh tiếng cho nhà văn.

Ngôn ngữ trong hai tập truyện ngắn Gió trên đồi hoang và truyện ngắn Đất còn phù sa mang đậm chất dân dã và chất phương nẫu. Điển hình là những từ địa phương được tác giả sử dụng khá nhiều trong các lời đối thoại và lời văn một cách rất tự nhiên. Các từ mà những người dân đất Phú hay dùng hàng ngày như: Ổng, chực, chìu, “Ổngcho em nghỉ cả ngày” [1, tr.66], "từng bầy két xanh chục vắng người là ào xuống đậu rạp cả trảng” [2, tr.154], "hắn chùiđôi tay cáu bẩn vào ống quần bết bụi, cẩn thận hơn đếm đi đếm lại các tấm màn cho ba hồi sáu cảnh ở vở Lục Vân Tiên" [2, tr. 8] mang lại sự gần gũi, dân dã.Đây cũng là những cách xưng hô mang tính thân mật, có khi đến suồng sã cũng xuất hiện nhiều trong văn. Ngôn ngữ đời thường được nhà văn đưa vào trong tác phẩm một cách rất tự nhiên. Mặc dù trong truyện ngắn xuất hiện nhiều nhân vật mang nhiều tầng lớp khác nhau nhưng những từ dân quê, bình dị cũng hiện diện nhiều trên các trang văn. Đặc biệt, tác giả đã sử dụng khá nhiều khẩu ngữ mang đậm đặc trưng vùng Nam trung bộ. Các từ mà Huỳnh Thạch Thảo dùng thể hiện những trạng thái buồn vui, khinh khi như: "Quân phục ủi hồ" [1, tr15], "zoọt thôi” [1, tr.38], "Đ.m tan nát sânbay rồi”[2, tr. 38], “Các ông chạy giỏi $\boldsymbol{d} \tilde{\boldsymbol{u}}$ vậy” [1,tr. 41]", "Phủi đít" [2, tr.13], "nuốt ỵc ly rượu" [2, tr.29], "chầu hẫu ra miệng" [2, tr.30], "ngốn ngấu” [2, tr.30], “trắng ởn" [2, tr.30], “hả họng nhìn tao"'[2, tr.31], "tô nước” [2, tr.31], “tao đu nguời lên cổng” [2,tr.35], "Miệng mấm, miệng múi, anh chết thì... ở... chó a, a ia..."[2, tr.62], "bận xà lên” [2, tr.85], “đàn chim bu kín” [2, tr. 85].

Việc sử dụng khẩu ngữ, ngôn ngữ dân dã, truyện ngắn Huỳnh Thạch Thảo đã tạo ra giọng văn gần gũi, thân mật, mang nhiều nét hồn nhiên cho mỗi câu văn. Những ngôn ngữ phiếm chỉ lại được tác giả sử dụng rất nhiều trong việc gọi tên các nhân vật: chị Hảo, anh Ba, anh Năm, anh Tư (Đất lề), chị (Người đàn bà ở bến sông Ngân), người lái xe lâm trường, em gái anh (Bên kia đèo mây), thằng Hào (Gió trên đồi hoang), hắn, thằng Sầm, ông lão giữ đình (Huyền thoại làng), tụi mày, nó, gã (Đêm nơi tháp cổ).

Qua việc khảo sát về cách xưng hô cũng như việc gọi tên của nhân vật, chúng tôi nhận thấy nhà văn Huỳnh Thạch Thảo đã tạo nên nét văn phong riêng trong quá trình sáng tác của mình. Từ những số phận 
nhân vật, nghề nghiệp, tính cách, tuổi tác, tên gọi đến tâm sinh lý cũng được xây dựng và khắc hoạ mang đậm tính chất vùng miền. Dù văn hoá Bắc - Nam có sự giao thoa với nhau trong cùng một đất nước nhưng nét đặc trưng văn hoá vùng miền vẫn sẽ không bao giờ thay đổi theo thời gian lịch sử. Chính yếu tố đó tạo nên sự đa dạng và phong phú bản sắc dân tộc Việt Nam.

\section{Kết luận}

Qua việc khảo sát hai tập truyện Giótrên đồi hoang và Đất còn phù sa của nhà văn Huỳnh Thạch Thảo, chúng tôi khái quát được một số điểm nổi bậc nhất về nội dung mà anh hướng đến. Thiên nhiên nhẹ nhàng bên cạnh dữ dội, đơn sơ cùng với đó là hình ảnh những người dân lao động nghèo khổ, cơ cực bên dòng sông Ba quen thuộc. Với thời gian hối cố, trong không gian quá khứ, Phú Yên thời chiến tranh ác liệt, tan thương cũng hiện diện cụ thể trên từng trang truyện ngắn. Qua các tác phẩm của mình, Huỳnh Thạch Thảo đã thể hiện tình yêu quê hương đất nước vô bờ bến và sự đam mê sáng tác. Qua việc chuộng sử dụng ngôn ngữ mang đậm chất dân quê và đậm chất phương nẫu, Huỳnh Thạch Thảo đã góp phần làm nên sự phát triển về thơ văn tỉnh nhà trong nền văn học chung của đất nước.

\section{TÀI LIỆU THAM KHẢO}

1. Huỳnh Thạch Thảo (1999), Gió trên đồi hoang, Nxb Hội nhà văn, Hà Nội;

2. Huỳnh Thạch Thảo (2001), Đất còn phù sa, Nxb Hội nhà văn, Hà Nội.

\section{Some significant characteristics in "Alluvial soil and wind on the hills" of Huynh Thach Thao}

Truong Thi Thu Thanh

\section{Article info}

Recieved:

27/02/2018

Accepted:

$10 / 9 / 2018$

Keywords:

Huynh Thach Thao, short story of Huynh

Thach Thao, Soil also

silt, Wind on the hill.

\begin{abstract}
Coming to Phu Yen literary arts, readers can not ignore the author Huynh Thach Thao - one of the most prominent authors in the short story style with his passion, inspiration and aspiration from the hometown. The works of Huynh Thach Thao bring many details of nature and the world with gentle tone in the author's own style.
\end{abstract}

